\title{
The adoption of sustainable development indicators in agricultural practices in the Gharb region (Morocco)
}

\author{
Sami Chbika ${ }^{1}$, El Mahjoub Aouane ${ }^{1}$ \\ ${ }^{1}$ Faculty of Sciences, Biology Department, 14000 Av. de L'Université, Kénitra, Morocco
}

\begin{abstract}
Many studies were carried out in Morocco to show that the dynamics of the market gardening is characterized by frequent use and often uncontrolled use of chemical inputs to the detriment of the preservation of natural resources, the health of consumers and the producers themselves. This reality, calls for appropriate structural actions, based on the levels of sustainability of the sector. The IDEA method (Farm Sustainability Indicators) is one way of giving practical expression to the concept of sustainable farms. Based on 40 sustainability indicators covering the three dimensions of sustainability: agro-ecological, socioterritorial, and economic. Using the IDEA method, we conducted this research with a view to analyze the sustainability of market gardening exploitations in three rural communities: Mnasra, Sidi Mohamed Benmansour, and Benmansour. We conducted questionnaire interviews with 180 producers. The results obtained have generally shown that the market gardening farms in this region have low sustainability scores. The sustainability of farms is lowest on the socio-territorial scale due to the absence of product quality approaches, poor human development, and poor employment conditions and services. On the economic scale, the low viability stands out. The agro-ecological scale shows higher values due to the good organization of space and diversified systems.
\end{abstract}

\section{Introduction}

The only growth that can be described as development is the one that shows progress on all three aspects of economic, social, and ecological plans at once.

Sustainable development seeks to simultaneously take into account social equity, economic efficiency, and environmental quality. It represents a break with other modes of development deemed unsustainable over time, since they have generated significant social and ecological damage, at global and local levels.

However, the current growth model is certainly not leading to sustainable development.

Globally, ecological balances are broken and very little will be done to fix it.

Growth in agriculture consists of achieving productivity gains (intensification, lower production costs, reduction in the arduousness of the work) due to the combination of efficient use of resources and technological innovations. However, there are risks in terms of renewing resources, but also mastering technologies. These risks are classified into risks of loss of resources, degradation of the environment, quality of life, and health of populations.

The Moroccan agricultural sector plays an important role in the national economy and contributes 15 to $20 \%$ of the GDP (Gross domestic product) depending on the year. In this production, the share of cereals is around $35 \%$ and that of livestock from 26 to $32 \%$. It is the main employer nationally and represents $1 / 3$ of exports. In terms of population, the rural world nevertheless saw its share drop from $75 \%$ in 1960 to $49 \%$ in 1994 and it is expected, according to CERED that it will only represent nearly $27 \%$ of the population in 2025 [1]

Several scientific studies carried out in Morocco show that the current market garden production dynamic is characterized by frequent and often uncontrolled use of chemical inputs to the detriment of the preservation of natural resources, the health of consumers, and of the producers themselves $[2,3]$

Today, the immediate response to the growing demand for food production is the intensive use of agrochemicals, which largely include fertilizers and pesticides [4]. In addition, with the development of resistant populations of pests, each year greater amounts and new chemicals are used to protect crops [4, 5].

Each year, around 2.7 million tonnes of active ingredients are used globally in the environment, especially in agriculture, to prevent crop losses [6].

In Morocco, according to statistics from the foreign exchange office, imports of plant protection products have not stopped increasing since $2005[7,8]$.

According to the agricultural development agency, industrial fertilizers will increase to more than 1.6 million tonnes in 2020 [9], while the protection and restoration of Moroccan aquatic ecosystems constitute a priority formalized by Law 10-95 with the objective of maintaining and improving the aquatic environment by guaranteeing good water quality [10]. 
In 2008 King Mohammed VI, launched 'the Green Morocco Plan' (PMV) consisting of a series of initiatives to help farmers, especially in remote regions and the countryside, to continue to meet their daily needs through the rational use of resources based on a sustainability approach. The determination of indicators evaluates the sustainability of the farms with a view to guiding development policies in the agricultural sector towards more sustainability.

In Morocco, the development dynamic of the irrigated production sector was supported under the Green Morocco Plan. However, the sustainable development of the market gardening sector is severely hampered by the degradation of natural resources under the impact of inappropriate cultivation practices in a context of climate change, demographic pressure, and the economic vulnerability of stakeholders. Therefore, it is important to be concerned about the sustainability of the sector, as agricultural land is no longer expandable and climatic hazards are recurring.

In this perspective, an analysis of the sustainability of market gardening operations in Morocco will make it possible to identify the strengths and weaknesses of current vegetable production methods, in order to develop and promote locally more appropriate production systems and techniques, which are real prerequisites to more sustainable agriculture. The main challenge of this analysis of market gardening is the development of innovative and resilient strategies that will ensure sustainable quality and satisfactory market gardening productivity while preserving environmental resources and the health of populations.

Thus, with regard to the above-mentioned imperatives, we set ourselves within the framework of this article the objective of analyzing the sustainability of market gardening operations in the three rural municipalities studied on the basis of the development indicators method (according to the IDEA method).

Our research is based on the hypothesis that market gardening operations in this region of Morocco are not sustainable. This hypothesis stems from the results of scientific research and several reports, indicating that current vegetable production methods are mainly marked by frequent, even systematic, and often uncontrolled use of chemical inputs and a low level of management production spaces.

\section{Assessment of the sustainability of farms}

The overall objective of this study is to measure the sustainability of farms in the irrigated areas in this coastal area of Gharb. This area is characterized by the presence of an aquifer system with significant potential in water resources. This undeveloped area has experienced great agricultural development thanks to a private irrigation extension of underground pumping. The technological development of pumping equipment has made it possible to reach great depths at relatively low costs.

However, the intensive use of groundwater as the only water source could lead to its overexploitation and subsequently the advance of the salt wedge.
The aim is to identify the socio-economic and environmental impacts of this dynamic of territorial transition by the method of sustainability indicators for agricultural holdings (IDEA). However, before resorting to the said technique, a technical and socio-economic diagnosis of the irrigated perimeters is carried out. The data collected will be analyzed and interpreted to understand the functioning of these perimeters.

The IDEA method is characterized by 40 indicators structured within 11 components and three sustainability scales: agro-ecological, socio-territorial, and economic $[11,12]$ (Tables 1, 2, 3).

Table 1: The 13 indicators in the agro-ecological sustainability scale

\begin{tabular}{|c|c|c|}
\hline \multirow{3}{*}{$\begin{array}{l}\stackrel{\overrightarrow{0}}{0} \\
\stackrel{0}{0} \\
\stackrel{D}{0}\end{array}$} & A1 & Diversity of annual or temporary crops \\
\hline & A2 & Diversity of perennial crops \\
\hline & $\overline{\mathrm{A} 3}$ & $\begin{array}{l}\text { Enhancement and conservation } \\
\text { of genetic heritage }\end{array}$ \\
\hline \multirow{3}{*}{$\begin{array}{c}\text { Organi } \\
\text { zation } \\
\text { of } \\
\text { space } \\
\end{array}$} & $\mathrm{A} 4$ & Dimension of fields \\
\hline & A5 & Rotation \\
\hline & A6 & Ecological buffer zones \\
\hline \multirow{7}{*}{ 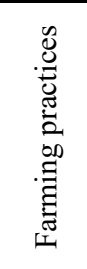 } & A7 & Fertilization \\
\hline & A8 & Pesticides and veterinary products \\
\hline & A9 & Soil resource protection \\
\hline & A10 & Water resource protection \\
\hline & A11 & Energy dependence \\
\hline & A12 & Management of chemical packaging \\
\hline & $\overline{\mathrm{A} 13}$ & Management of production waste \\
\hline
\end{tabular}

Table 2: The six indicators in the economic sustainability scale

\begin{tabular}{|l|l|l|}
\hline $\begin{array}{l}\text { Economic } \\
\text { viability }\end{array}$ & C1 & $\begin{array}{l}\text { Economic viability of the } \\
\text { exploitation }\end{array}$ \\
\cline { 2 - 3 } & C2 & Economic specialization rate \\
\hline Independence & C3 & Financial Autonomy \\
\cline { 2 - 3 } & C4 & Aid Sensitivity (AS) \\
\hline efficiency & C5 & Economic efficiency of production \\
\hline Transferability & C6 & $\begin{array}{l}\text { Socio-economic transferability of } \\
\text { the exploitation }\end{array}$ \\
\hline
\end{tabular}

\subsection{The agro-ecological dimension}

The agro-ecological dimension analyzes "the propensity of the production system to combine both efficient use of the environment and minimum ecological cost". According to Zucchini et al, (2016) [13], the indicators of this dimension make it possible to assess the production methods having an impact on the environment and its way of life. The components of the agro-ecological dimension of IDEA are Diversity, spatial organization, and agricultural practices (Table 1).

\subsection{The socio-territorial dimension}

The socio-territorial dimension relates to the IDEA method in the externalities generated by the exploitation for the producer as well as for the social environment in which he works. It analyzes the local and global social impact fulfilled by exploitation. In particular, the socio-territorial sustainability scale relates to the degree of integration of the 
exploitation in its territory and in society (Zucchini et al. 2016) [13]. It assesses the quality of production, the quality of life of the producer, and the services he provides to the territory and to society (Table 3 ).

Table 3: The 21 indicators in the socio-territorial sustainability scale

\begin{tabular}{|c|c|c|}
\hline \multirow{3}{*}{$\begin{array}{l}\text { Quality of } \\
\text { the products } \\
\text { and land }\end{array}$} & $\mathrm{B} 1$ & Mode of production \\
\hline & $\mathrm{B} 2$ & $\begin{array}{l}\text { Enhancement of buildings and } \\
\text { landscape heritage }\end{array}$ \\
\hline & B3 & Accessibility of space \\
\hline \multirow{6}{*}{$\begin{array}{l}\text { Employment } \\
\text { and service }\end{array}$} & B4 & Services, multi-activity \\
\hline & B5 & Quality of customer reception \\
\hline & B6 & $\begin{array}{l}\text { Contribution to the development of } \\
\text { local resources }\end{array}$ \\
\hline & B7 & Direct contribution to employment \\
\hline & B8 & Collective work \\
\hline & B9 & Sustainability of the activity \\
\hline \multirow{9}{*}{$\begin{array}{c}\text { Ethics and } \\
\text { human } \\
\text { development }\end{array}$} & B10 & Contribution to world food balance \\
\hline & B11 & $\begin{array}{l}\text { Degree of transparency on the quality } \\
\text { of the products sold }\end{array}$ \\
\hline & B12 & Training \\
\hline & B13 & Labor intensity \\
\hline & B14 & Quality of life \\
\hline & $\mathrm{B} 15$ & Hygiene and safety \\
\hline & B16 & $\begin{array}{l}\text { Geographical and socio-cultural } \\
\text { isolation }\end{array}$ \\
\hline & B17 & $\begin{array}{l}\text { Acceptability of the implementation by } \\
\text { the neighborhood }\end{array}$ \\
\hline & B18 & $\begin{array}{l}\text { Participation in the development of } \\
\text { sector policies }\end{array}$ \\
\hline \multirow{3}{*}{$\begin{array}{l}\text { Gender and } \\
\text { production } \\
\text { process }\end{array}$} & B19 & $\begin{array}{l}\text { Gender involvement in the realization of } \\
\text { production activities }\end{array}$ \\
\hline & $\mathrm{B} 20$ & $\begin{array}{l}\text { Autonomy of management of income } \\
\text { from production by gender }\end{array}$ \\
\hline & B21 & $\begin{array}{l}\text { Psycho-sociological consideration of } \\
\text { women's participation in market } \\
\text { gardening }\end{array}$ \\
\hline
\end{tabular}

\subsection{The economic dimension}

The economic dimension of the IDEA Method is concerned with the farm's ability to maintain its economic performance over the medium and long term despite the vagaries of the economy [12]. It analyzes beyond the overall economic performance of the operation, the economic or financial profitability, the degree of economic independence, the transferability, and the efficiency of the production process [12]. It is made up of indicators relating to the following components: economic viability, economic independence, transferability, and efficiency of the production system (Table 2).

\section{Material and methods}

\subsection{Characterization of the study area}

This study was carried out in the rural regions of Mnasra, Sidi Mohamed Benmansour, and Benmansour. It covers an area of around $488 \mathrm{~km}^{2}$ between the south of Kénitra and the north of Moulay Bousselham lagoon (Fig. 1). The economy of this area is based on agriculture and multiactivity. It is a good example of a vulnerable rural area, where the assessment of sustainability poses particular problems: it is difficult to have information because little data exists, and no statistics in these pluriactive farms.

It is a coastal area with an unimpressive dune landscape, with altitudes that rarely exceed $60 \mathrm{~m}$. This area has an elongated shape parallel to the coastline. It is about $60 \mathrm{~km}$ long and much narrower in the southern part (approximately $7 \mathrm{~km}$ ) than in the northern part (12 to 15 $\mathrm{km})$.

In total, the population of the three municipalities considered now exceeds 97,000 inhabitants (HCP, 2014), whereas it was only around 30,600 inhabitants in 1971 .

Until the end of the 1980s, land development was based on subsistence agriculture based on cereals associated with extensive sheep farming on natural ranges. Only the southern part, close to Kénitra, stood out for its market gardening. The intensive high-tech agriculture that was previously developed makes widespread use of irrigation from easily accessible underground water.

The climate is the Mediterranean. With an average rainfall of $564 \mathrm{~mm}$ at the Mnasra station (Fig. 2), the area is located among the moderately rainy regions of Morocco. But the rains are very irregular from year to year. The rainy season lasts from October to April, with a maximum in December (110 mm). For this month, from 1973 to 2010, the values vary from 0 (in 1974) to $338 \mathrm{~mm}$ (in 1997). The months of June to September have very little rainfall and those from June to August each receive less than $5 \mathrm{~mm}$ on average.

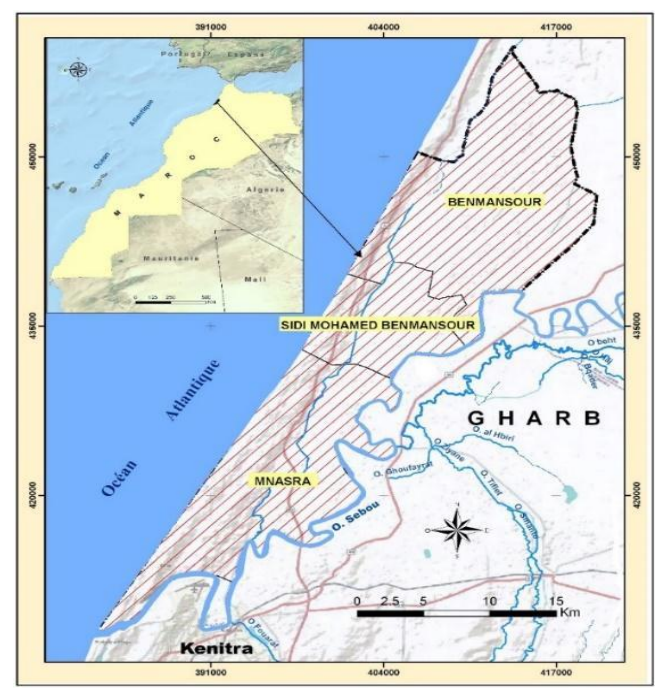

Figure 1: Location of the study area.

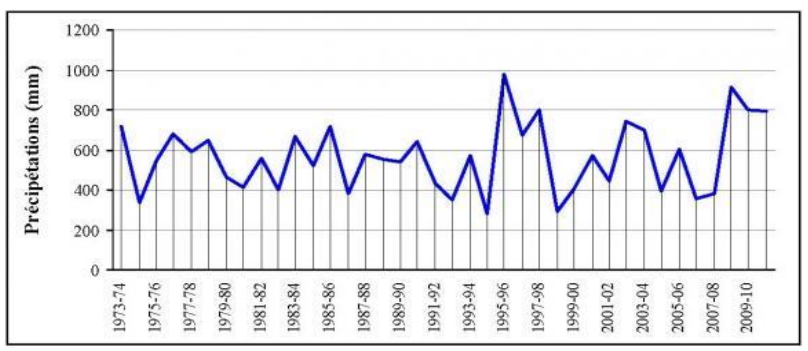

Figure 2: Annual precipitation at the Mnasra station (from September 1973 to August 2011). 


\subsection{Choice of the sustainability assessment method: IDEA}

We choose the IDEA method (farm sustainability indicators) which is based mainly on the agricultural activities of rural households. This method has been applied in African countries (notably Congo, Senegal, Benin) but also in the Maghreb (Morocco, Algeria, and Tunisia). The IDEA method is first and foremost an educational tool which seeks not only to assess the sustainability of agricultural systems, but also advances the concept of sustainability by provoking debates and questions through each indicator, and by suggesting simple means adapted to each local situation to improve the sustainability and overall functioning of the system analyzed.

\subsection{Application of the method}

The IDEA method is characterized by 42 indicators structured within 10 components and three sustainability scales: agro-ecological, socio-territorial, and economic $[11,12]$. We started with exploratory surveys using the livelihoods framework [15] to understand how farms operate. Then the IDEA reference survey format was used to collect the information needed to calculate the indicators.

\section{i. Choice of sample}

To carry out our surveys, we have drawn up an exhaustive list of all the market gardening sites in the three municipalities. Then we randomly selected nine sites (three per municipality). We selected and interviewed 60 market gardeners per municipality, i.e. a total of 180 producers, during the 2019-2020 campaign.

These interviewed producers were chosen so as to geographically cover the studied area.

Rather, we sought to represent the diversity of situations encountered during previous research work in this region. Our sample, therefore, consists of 180 diversified farms.

\section{ii. Changes to IDEA indicators}

Calculating the pesticide indicator is complicated on small family farms because these farmers do not record the products they use, nor the doses they apply. Often, the lack of technical advice and the low level of education of farmers lead to the application of either excess or lack of pesticide doses. We, therefore, proposed modifications to the pesticide indicator based on data collected in the field, from a survey conducted with the main distributor of phytosanitary products in the study area. These modifications are defined by 3 modules. The first "dose" module positions the dose applied by the farmer in relation to the approved dose with a rating scale of 0 (no compliance with the dose) to 4 (compliance with the approved dose). The second "toxicity" module reflects the toxicity of the pesticide to the health of the person applying the product and to those around him. The toxicity can be acute in the short term when there is direct contact with the product or be chronic in the long term. The criteria taken into account for the scoring of this module is the degree of protection at the time of the application of pesticides and the preventive measures taken vis-à-vis other people before and after application (warn neighbors and put prevention signs). Finally, the third "risk" module corresponds to the impact of pesticides on the three main environmental compartments (groundwater, surface water, air).

The economic viability indicator has been adapted to the Moroccan context. In fact, the scale used by the IDEA method refers to the SMIC (minimum growth wage) used in France. We, therefore, used the SMIG (legal minimum wage), equivalent to the SMIC for Moroccan farms.

\section{iii. Statistical analyzes}

We applied the IDEA method to the 180 farms surveyed and assigned them a score for each of the 40 IDEA indicators. Given the small size of our sample, it was not possible to perform a principal component analysis from the scores on these 42 indicators. We have therefore grouped these 42 elementary indicators according to the ten components of IDEA which synthesize the main characteristics of the sustainability diagnosis.

\section{Results}

The survey data reveal that the agro-ecological dimension of market gardening farms in the region studied obtains an average score of 22.17 points $(22.17 \%$ of the potential maximum) with an observed maximum of 53 points (Table 4). It also shows that around $75.7 \%$ of farms have an agro-ecological sustainability score less than or equal to $30 \%$ of the maximum potential (Table 1 ).

Table 4: Descriptive statistics of the dimensions of agroecological, socio-territorial, and economic sustainability

\begin{tabular}{|l|c|c|c|}
\hline Statistics & $\begin{array}{c}\text { Agro- } \\
\text { ecological } \\
\text { dimension } \\
(100 \text { units })\end{array}$ & $\begin{array}{c}\text { Socio- } \\
\text { territorial } \\
\text { dimension } \\
\text { (100 units })\end{array}$ & $\begin{array}{c}\text { Economic } \\
\text { dimension } \\
(100 \text { units })\end{array}$ \\
\hline Observations & 180 & 180 & 180 \\
\hline Minimum & 9 & 23 & 17 \\
\hline Maximum & 53 & 81 & 91 \\
\hline 1st Quartile & 17 & 35 & 39 \\
\hline Median & 22 & 40 & 57 \\
\hline 3rd Quartile & 29 & 53 & 75 \\
\hline Mean & 22.17 & 38.23 & 55.9 \\
\hline $\begin{array}{l}\text { Standard } \\
\text { deviation }\end{array}$ & 11.3 & 5.3 & 6.9 \\
\hline $\begin{array}{l}\text { Coefficient of } \\
\text { variation }\end{array}$ & 0,51 & 0,13 & 0,12 \\
\hline
\end{tabular}

The socio-territorial dimension obtains an average score of 38.23 points $(38.23 \%$ of the potential maximum) with an observed maximum of 81 points (Table 4). In addition, $75 \%$ of farms obtained a socio-territorial sustainability score less than or equal to $50 \%$ of the potential maximum (Table 3 ).

As for the economic dimension, it obtains an average of 55.9 points ( $55.9 \%$ of the potential maximum) with an observed maximum of 91 (Table 4). 50\% of market 
gardeners obtained a score between $39 \%$ and $75 \%$ of the potential maximum (Table 2).

The results obtained on the three dimensions already show that the vegetable farms in the region studied have low levels of sustainability: in fact, the majority of the average scores do not reach half of their potential maxima.

\subsection{Agro-ecological sustainability analysis}

Made up of "Diversity", "Spatial organization" and "Agricultural practices" components, the weakness of the agro-ecological sustainability of market gardening operations in the region studied varies according to its different components. Thus the "Diversity" component obtained an average score representing $35.1 \%$ of its potential maximum (Table 4). In general, this shows that the region's market gardening farms are moderately diversified in terms of the crops produced.

As for the "spatial organization" component, it obtained an average score representing 38.91\% of its potential maximum. This weakness is brought about by the low score of the Rotation indicator representing $24.53 \%$ of its potential maximum. This indicates a low level of adoption of sustainable land-use techniques which have the advantage of improving soil fertility.

\subsection{Analysis of socio-territorial sustainability}

Socio-territorial sustainability is assessed through the scores obtained by its components " Product and territory quality ", " Jobs and services ", " Ethics and human development ", and " Gender and production". From our surveys, the "Product and territory quality" component obtains a score representing $11.2 \%$ of its maximum potential. This score is pulled down by the low average scores of the Mode of production, Valuation of built heritage, and the landscape, Accessibility of space indicators which constitute this component.

The "Employment and Services" component scores $51.23 \%$ of its potential maximum. This score is the result of the average scores of the Quality of customer reception and Collective work indicators which respectively reach $85.35 \%$ and $71.25 \%$ of their potential maximums and thus showing the strength of solidarity and mutual aid. between market gardeners as well as the highly commercial opening of market gardening in the region studied.

Regarding the "Ethics and Human Development" component, it obtains an estimated score of $27.53 \%$ of its maximum potential. By analyzing the score of its Services indicator, pluriactivity, it emerges that this reflects not only the lack of training of producers in the market gardening sector but also a low level of membership of producers in an umbrella structure of market gardeners. The said component is also pulled down by the indicators Contribution to the world food balance and the sustainable management of planetary resources and Intensity of work which obtained scores representing respectively $23.7 \%$ and $31.8 \%$ of their potential maxima. These results show that market gardening as it is practiced in the three municipalities is very physically demanding. However, the Quality of life and Health and safety at work indicators obtain $35.43 \%$ and $47.56 \%$ of their potential maximums respectively. This reality reflects the impact of market gardening in improving the living conditions of producer households.

As for the " Gender and market gardening " component, it obtained a relatively low score of $59.26 \%$ of its maximum potential despite its indicator " Gender involvement in the realization of production activities " which reached $81.23 \%$ of its maximum potential, thus indicating a strong contribution of women to the development of market gardening. However, the "Psychosocial Considerations of Women's Participation in Market Gardening" and "Management Autonomy" indicators show low scores $(31.2 \%$ and $28.53 \%$ of their potential maxima). These scores reveal the omnipresence of socio-cultural constraints to the detriment of an improvement in the conditions for better participation of women in the development of market gardening in Morocco.

\subsection{Economic sustainability analysis}

From the analysis of data relating to the " Viability ", " Efficiency ", " Independence " and " Transmissibility " components of the economic dimension, it emerges that the " Sustainability " component obtains a score representing $21.36 \%$ of its maximum potential. This low score is explained by the very low score obtained by the economic viability of the farm indicator $(6.23 \%$ of its maximum potential). These results show that in general, the farms considered are economically inefficient in the short and medium-term.

The "Independence" component scores $35.62 \%$ of its potential maximum. In terms of "Efficiency", the economic dimension obtains a score representing 59.3\% of its maximum potential. The good efficiency of farms in the region is supported by the Economic efficiency of the production indicator that constitutes it. This could be justified by the advantages on productivity and the profit of the experience in market gardening and the evergrowing enthusiasm for the practice of market gardening in the region. The "Transmissibility" component scores $59.32 \%$ of its potential maximum. This value reveals the existence of a desire on the part of the heirs to take over market gardening farms from their parents. This score could also be justified by the contribution of market gardening income in domestic investments made by producers.

\section{Discussion}

The scores of the various components of the agroecological, socio-territorial and economic dimensions are presented in Table 4. We observe that the components "Employment and service", "Efficiency" and "Transmissibility" present the best averages but also that the component " agricultural practices " obtains the lowest average score.

In general, the sustainability of market gardening operations in the three municipalities is low. This 
sustainability is strongly limited by its agro-ecological dimension (score of $22.17 \%$ of its maximum potential). This score reflects market gardening characterized by daily, even intensive, use of chemical inputs.

Indeed, the data collected shows that a considerable number of market gardeners use chemical pesticides and herbicides in a systematic way, without real consideration of their consequences on the environment, on their own health, and on the health of consumers.

However, from the perspective of an agroecological transition, it is wiser for each producer to prioritize the ingredients available in his immediate environment. This dynamic must be supported by research efforts in the production of locally improved seeds, granted by the country's research institutes in order to make local seeds available to producers and adapted to the agro-ecological context. This would involve making all of these imperatives part of an agricultural development policy based on sustainable agronomic practices.

With a score representing $38.23 \%$ of its maximum potential, the socio-territorial dimension shows that the social integration of farms is low. However, this weakness should be put into perspective. Indeed, socio-territorial sustainability is negatively influenced by the omnipresence of the conventional production method, and the poor development of production spaces (absence of a building storage material, access to the field often impractical).

In terms of gender involvement in market gardening, direct observation of production environments has revealed that women are mainly employed in plowing, transplanting, and collecting market garden products.

The " Gender and production process " component of the socio-territorial dimension is also influenced by the weakness of women's autonomy in the management of income from production, as well as by the persistence of socio-cultural constraints that hamper their participation in the development of market gardening. It is therefore imperative to carry out structural policies aimed at allowing equal access to the means of production between the different gender categories. In addition, from a perspective of socio-economic and environmental sustainability of market gardening operations, women and men should have the same rights and equal access to resources, training, and services relating to market gardening in Morocco.

It is on the economic dimension that the farms of the three municipalities are better positioned, reaching on average $55.9 \%$ of their maximum potential. The relative weakness of this dimension is due to the economic viability and autonomy of weak productions. Indeed, the capacity to secure income from production systems in the face of market fluctuations (in particular the instability of input prices) and daily contingencies are weak, also due to a lack of diversification.

\section{Conclusion}

Overall, the sustainability of farms is the lowest on the socio-territorial scale due to the absence of product quality approaches, poor human development, and poor conditions of employment and services. On the economic scale, it is the low viability that stands out. The agroecological scale shows higher values due to the good organization of space and diversified systems.

Improving the sustainability of farms with the lowest scores could be based on a strategy to add value to products and secure access to water.

However, it appears that some indicators (such as the transmissibility indicator) seem ill-suited to the Moroccan context, due to the cultural and religious framework. Its adaptation would require careful consideration, which was not carried out as part of this study, and would deserve to be carried out subsequently.

Finally, the numerous exchanges with farmers have highlighted a representation and an analysis of what the sustainability of the farm is quite different from those that support the sustainability assessment framework carried by scientists, in particular in IDEA. In this context, it seems necessary to continue thinking about the horizons of sustainability and the main dimensions seem to be understood by farmers. This could lead to the construction of participatory indicators and evaluation grids that farmers could better understand and use for decision support purposes.

\section{References}

1. CERED (Centre d'Etudes et de Recherches Démographique), Population et développement au Maroc, vingt-cinq ans après la conférence du Caire de 1994, Rapport 2019, Rabat, Maroc (2019)

2. Eddaya1, T., Boughdad, A., Becker, L., Chaimbault, P., Zaïd, A., Utilisation et risques des pesticides en protection sanitaire de la menthe verte dans le CentreSud du Maroc. J. Mater. Environ. Sci. 6(3) (2015) 656-665.

3. ONSSA (Office National de Sécurité Sanitaire des produits Alimentaires), Etude sur le suivi de l'effet des pesticides sur la santé humaine et l'environnement, Rapport final 2015, Rabat, Maroc (2015)

4. Carvalho, F.P., Agriculture, pesticides, food security and food safety. Environ. Sci. Pol. 9, 685-692 (2006)

5. Popp, J., Pető, K., Nagy, J., Pesticide productivity and food security. A review. Agron. Sustain. Dev. (2013) 33:243-255.

6. EPA, Pesticides Industry Sales and Usage, 20082012 Market Estimates. United States Environmental Protection Agency, Washington D.C. (2017)

7. El Ouilani B., Article sur le marché des produits phytosanitaires au Maroc. http://www.abhatoo.net.ma/maalamatextuelle/developpement-economique-etsocial/developpementconomique/agriculture/technique-culturale/articlesur-le-marche-des-produits-phytosanitaires-aumaroc (2017)

8. NAAMANE, A., SADIQ, A., BELHOUARI, A., IOUNES, N., EL AMRANI, S., Enquête sur 
l'utilisation des engrais et pesticides chez les agriculteurs de la région de Casablanca-Settat. Rev. Mar. Sci. Agron. Vét. (2020) 8(3) : 279-285.

9. PCN., Plan Cadre National pour les MCPD. Plan sectoriel «agriculture et alimentation durables» Maroc, 2016.

10. Salman M.A., Bradlow D., Regulatory Frameworks for Water Resources Management: A Comparative Study. WATER P-NOTES (June 2008) 9:1-4.

11. Briquel, V., Vilain, L.J.L., Bourdais, Girardin, P., Mouchet, C., Viaux, P., "La méthode IDEA (indicateurs de durabilité des exploitations agricoles) : une démarche pédagogique", Ingénieries - E A T 2001(25) : 29-39.

12. Vilain, L.D., Boisset, K., Girardin, P., Guillaumin, A., Mouchet, C., Viaux, P., Zahm, F. Eds, La méthode IDEA : indicateurs de durabilité des exploitations agricoles : guide d'utilisation. Approches, Dijon, Educagri Editions (2008)

13. Zucchini E., Faye A., Ngom Y. and Diémé R., Méthode IDEA, 39 p. (2016)

14. HCP (Haut-commissariat au plan), Recensement général de la population marocaine. Rabat, Maroc (2014)

15. Scoones, I., Sustainable rural livelihoods: A framework for analysis. Institute of Development Studies at the University of Sussex, Brighton (1998) 